\title{
Plasma Phencyclidine Pharmacokinetics in Dog and Monkey Using A Gas Chromatography Selected Ion Monitoring Assay ${ }^{\dagger \dagger}$
}

\author{
A. E. Wilson and E. F. Domino \\ Department of Pharmacology, The University of Michigan, Ann Arbor, Michigan 48109, USA \\ and Lafayette Clinic, Detroit, Michigan 48207, USA
}

\begin{abstract}
Phencyclidine was determined by gas chromatography selected ion monitoring in six dogs and seven monkeys. Aliquots of venous blood were taken over $4 \mathrm{~h}$ in the monkey after $1.1 \mathrm{mg} \mathrm{kg}^{-1}$ and over $24 \mathrm{~h}$ in the dog after $1.0 \mathrm{mg} \mathrm{kg}^{-1}$ of phencyclidine i.v. Pentadeuterated phencyclidine was used as the internal standard. In the electron impact mode the most abundant fragments in the mass spectrum of phencyclidine were $m / e 91$ and 200 , and 96 and 205 in the $\left[{ }^{2} \mathrm{H}_{5}\right]$ phencyclidine spectrum. These fragments were used to quantitate the amount of phencyclidine present. In both species, a complex exponential decline of plasma phencyclidine was found in most animals that fit a two compartment open model. In monkeys, the mean half-life ( $\beta$ phase) was $2.36 \mathrm{~h}$ and in the dog it was $2.86 \mathrm{~h}$. Compared with the monkey, the dog exhibited considerable emergence delirium. The two species had rather different pharmacokinetics which may be relevant to the observed differences in degree of anesthesia and recovery.
\end{abstract}

\section{INTRODUCTION}

In recent years the need to identify phencyclidine [PCP, 1-(1-phenylcyclohexyl) piperidine] in biological fluids and tissues has become important. This drug is increasingly abused. A number of clinical reports on human overdose cases have appeared ${ }^{1-5}$ Previous means of detection of PCP by chromatography and fluorometry ${ }^{6,7}$ are not specific. Gas chromatography mass spectrometry has done much to advance our knowledge in this field. ${ }^{8-14}$ Since PCP undergoes thermal decomposition above temperatures of $150^{\circ} \mathrm{C}$ to form 1-phenyl-cyclohexene, ${ }^{11,12}$ temperatures in all phases of the experiment must be carefully controlled. $A$ number of investigators ${ }^{11-14}$ have reported quantitative GCMS assays for PCP. We have adapted the GCMS chemical ionization (methane) assay of Lin $e t$ $a l^{12}$ for electron impact (EI). We have used GC selected ion monitoring to assay PCP in the plasma of the dog and monkey and have determined its plasma pharmacokinetics as described in this report.

\section{EXPERIMENTAL}

\section{Animals}

Six mongrel dogs of either sex were fasted $12 \mathrm{~h}$ prior to being given $1.0 \mathrm{mg} \mathrm{k}^{-1}$ PCP $\mathrm{HCl}$ i.v. calculated as

$\dagger$ Preliminary paper presented before the American Society for Pharmacology and Experimental Therapeutics: A. E. Wilson and E. F. Domino, Pharmacologist 18, 142 (1976).

$\ddagger \mathrm{PCP}=$ phencyclidine $\left.;{ }^{2} \mathrm{H}_{5}\right] \mathrm{PCP}=$ pentadeuterated phencyclidine

(C) Heyden \& Son Ltd, 1978 base. Control bloods were taken prior to the injection of PCP. Blood was collected from an indwelling venous cannula for $24 \mathrm{~h}$ during which time the dogs were allowed complete freedom of movement. PCP was given over a 1 min period.

Seven former morphine dependent Macaca mulatta monkeys of either sex were used in these experiments. At the time they were given PCP they had completely recovered from their narcotic dependence for 3-6 months. These animals were not on any medication. The animals were given $1.1 \mathrm{mg} \mathrm{kg}^{-1}$ of PCP $\mathrm{HCl}$ i.v. over $1 \mathrm{~min}$ with the dose calculated as base. Venous blood samples were collected over a $4 \mathrm{~h}$ period from an indwelling venous catheter. In both groups of animals all blood removed was replaced by an equal volume of $0.9 \% \mathrm{NaCl}$. Whole blood was collected in heparinized tubes, spun at $1000 \mathrm{~g}$ for $15 \mathrm{~min}$ and the plasma removed for PCP extraction.

\section{Assay}

The method of Lin et al. ${ }^{12}$ was used to extract PCP. Briefly, this involves adding $1 \mu \mathrm{g}$ of pentadeuterated PCP $\left(\left[{ }^{3} \mathrm{H}_{5}\right] \mathrm{PCP}\right)$ to the sample, buffering to $\mathrm{pH} 9.5$ and extracting twice with hexane. A back extraction was done into $0.2 \mathrm{~N} \mathrm{H}_{2} \mathrm{SO}_{4}$. After removal of the organic layer, the aqueous phase was buffered to $\mathrm{pH} 9.5$ for a final extraction into hexane. The hexane layer was removed and evaporated to dryness. One to $2 \mu$ l of the reconstituted sample in $25 \mu \mathrm{l}$ of hexane was used for GCMS analysis. In this study a Finnigan 3200 quadrapole gas chromatograph mass spectrometer with a 6102 data system was used in the EI mode. The GC conditions were with a column temperature of $190^{\circ} \mathrm{C}$ and injection port of $200^{\circ} \mathrm{C}$ to minimize thermal decomposition of PCP. Helium flow was $20 \mathrm{ml} \mathrm{min}^{-1}$. 
A $5 \mathrm{ft} \times 2 \mathrm{~mm}$ glass column was packed with $2.5 \% \mathrm{SE}$ 30 on Chromasorb G or $3 \%$ OV -17 on Gas Chrom Q. Two different columns were used since the OV-17 column separated a small interfering peak in recording $m / e 200$ in the selected ion profile of the monkey plasma. The glass jet separator was at $210^{\circ} \mathrm{C}$ to prevent sample condensation in the jet tip. All other lines were glass lined. The fragments were produced by EI at $70 \mathrm{eV}$.

\section{Pharmacokinetic analysis}

The number of compartments in an open compartment model was determined by an Amdahl $470 \mathrm{~V} / \mathrm{C}$ computer using the method of Wagner et al. ${ }^{15}$ The exponential equation to describe a multicompartment model was

$$
C=A e^{-\alpha t}+B e^{-\beta t}+\cdots
$$

where $C$ is the concentration at any time, $t, A$ and $B$ are constants for each compartment of which $\alpha$ and $\beta$ are exponents. A two compartment open model is shown below in which the phencyclidine was introduced directly into the plasma compartment:

$$
\begin{aligned}
& \text { Drug at site } \stackrel{K_{1}}{\longrightarrow} \text { Drug in plasma } \kappa_{2} \text { Drug } \\
& \text { of administration } \longrightarrow \text { A compartment } \longrightarrow \text { eliminated } \\
& K_{12} \downarrow K_{21} \\
& \text { Drug in tissues } \\
& B \text { compartment }
\end{aligned}
$$

The parameters $A, B$ and $\alpha, \beta$ were determined by a curve stripping program and $C o, K_{2}, K_{21}$ and $K_{12}$ were found by a nonlinear regression program [Wagner, personal communication (1977)]. The rate constants of the model were calculated as $K_{2}=1 /\left(A^{\prime} / \alpha+B^{\prime} / \beta\right)$ $K_{21}=A^{\prime} \beta+B^{\prime} \alpha, K_{12}=A^{\prime} B^{\prime}(\beta-\alpha)^{2} / K_{21}$ where $A^{\prime}=$ $A / A+B$ and $B^{\prime}=B / A+B$.

\section{RESULTS}

The combination of GCMS in the selected ion monitoring mode gives a very sensitive and quantitative means for determining PCP. With the use of $\left[{ }^{2} \mathrm{H}_{5}\right] \mathrm{PCP}$ as the internal standard, other possible drugs and materials found in biological samples can be avoided. In Fig. 1 is illustrated a total ion chromatogram (TIC) of $1 \mu \mathrm{g}$ of PCP and $\left[{ }^{2} \mathrm{H}_{5}\right] \mathrm{PCP}$ each added to monkey plasma. Since the final amount is concentrated in 20 $25 \mu \mathrm{l}$ of hexane, these peaks represent $40-50 \mathrm{ng}$ when $1 \mu l$ is injected. The mass spectra of PCP and $\left[{ }^{2} \mathrm{H}_{5}\right] \mathrm{PCP}$ are illustrated in Fig. 2. Note the molecular ions $m / e 243$ and $m / e 248$ are present but are of relatively low intensity as if often true of EI produced spectra. The base peak of PCP is $m / e 200$ and 205 for $\left[{ }^{2} \mathrm{H}_{5}\right]$ PCP. In view of the fact that $m / e$ 91, 96, 200 and 205 represent the major fragments of both $\mathrm{PCP}$ and $\left[{ }^{2} \mathrm{H}_{5}\right] \mathrm{PCP}$, these were monitored to obtain a standard calibration curve. The $m / e 91,96$ peak area ratios were monitored as a qualitative check for PCP while $m / e$ 200, 205 peak area ratios were used to determine the amount of PCP present. With this method of ex-

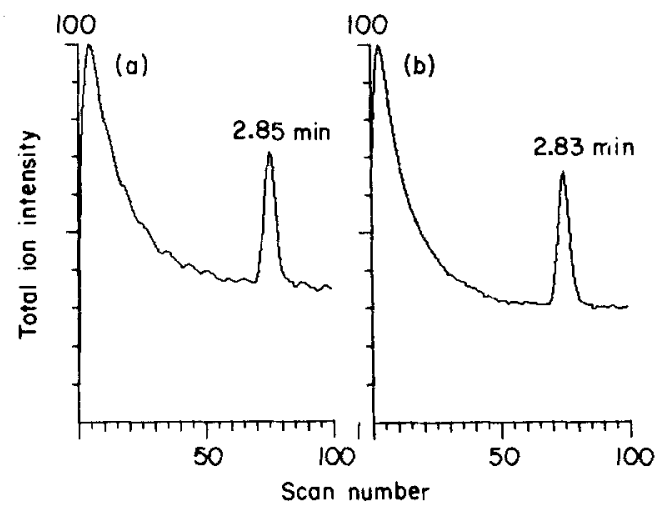

Figure 1. Total ion chromatogram of (a) phencyclidine and (b) $\left[{ }^{2} \mathrm{H}_{5}\right]$ phencyclidine. PCP and $\left[{ }^{2} \mathrm{H}_{5}\right] P C P\left(1 \mu \mathrm{g} \mathrm{mi}^{-1}\right)$ were run separately under the conditions listed. $\left[{ }^{2} \mathrm{H}_{5}\right] \mathrm{PCP}$ has a slightly shorter retention time, indicating an isotope effect. Conditions were as follows: Col. $=3 \%$ OV-17; Sol. $=$ hexane; Col. temp. $=$ $190^{\circ} \mathrm{C}$; Sep. temp. $=210^{\circ} \mathrm{C}$; He flow $=20 \mathrm{cc} \mathrm{min}^{-1}$.

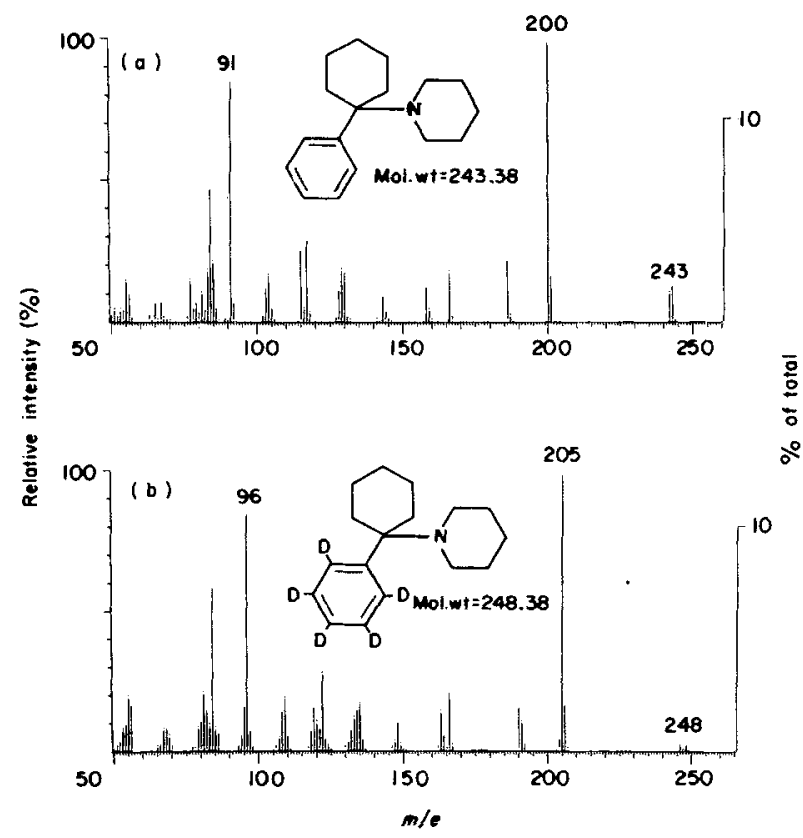

Figure 2. Mass spectra of (a) phencyclidine and (b) $\left[{ }^{2} \mathrm{H}_{6}\right]$ phencyclidine. Note that the major ions of PCP, m/e 91, 200 and 243 , are $5 \mathrm{~m} / \mathrm{e}$ higher for $\left[{ }^{2} \mathrm{H}_{5}\right] \mathrm{PCP}$.

traction, PCP metabolites are not extracted. Their retention times are also known to be different from that of PCP. ${ }^{12}$

A typical mass fragmentogram is illustrated in Fig. 3. It can be noted that there are no interfering constituents in the plasma sample. With a TIC $100 \mathrm{ng}$ was the limit of detectability; in selected ion monitoring 5 ng could be easily detected. A standard curve for PCP in dog and monkey plasma is shown in Fig. 4. Determinations were done to $0.1 \mathrm{ng}$; however, they are not indicated on the graph. The peak area ratio of 200/205 was used to quantitate the amount of PCP present. A recovery check was done by splitting six samples with an unknown endogenous amount of PCP and adding a known amount of PCP to one-half of each sample in addition to $1 \mu \mathrm{g}$ of $\left[{ }^{2} \mathrm{H}_{5}\right] \mathrm{PCP}$. The amount of exogenous PCP added to each half was calculated as 


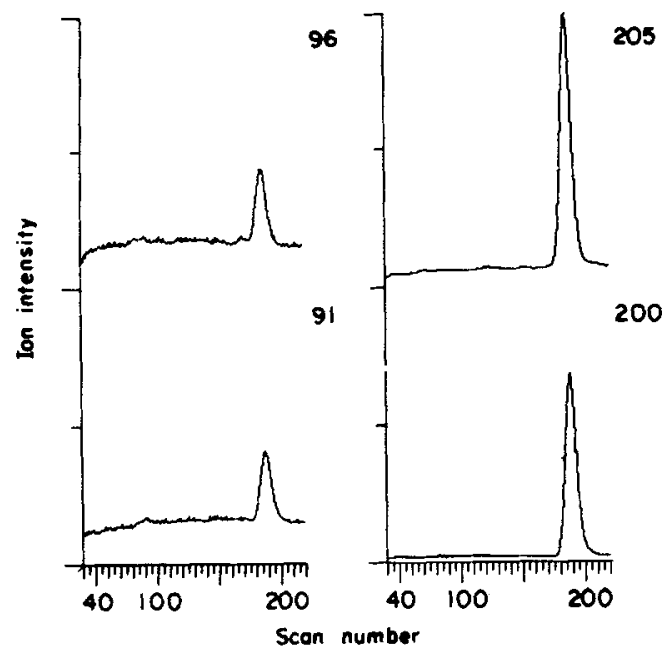

Figure 3. Selected ion profile of phencyclidine from monkey plasma using $\left[{ }^{2} \mathrm{H}_{5}\right]$ phencyclidine as the internal standard. This is a typical run on a monkey plasma sample in which slightly less PCP is present than the $\left[{ }^{2} \mathrm{H}_{5}\right]$ internal standard.

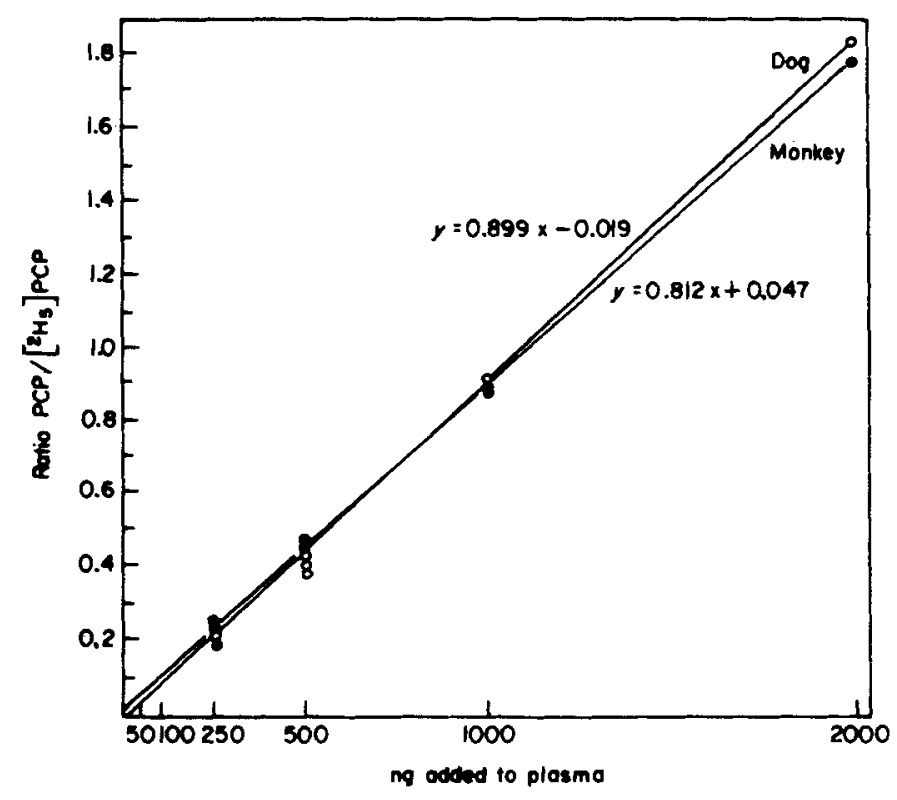

Figure 4. Standard calibration for phencyclidine in dog and monkey plasma using El selected ion monitoring. Note linearity of increasing amounts of $P C P$ added to the plasma samples with $\left[{ }^{2} \mathrm{H}_{5}\right]$ PCP constant at $1000 \mathrm{ng}$. Approximately $1 / 20(1 \mu \mathrm{l})$ of the final volume was injected into the gas chromatograph mass spectrometer. The $x$-axis represents added standards in $1 \mathrm{ml}$.

recovery and found to be $96.6 \%$. All samples were run two to three times and never varied more than $\pm 6 \%$ from the mean. Plasma samples determined from the calibration curve had a $\mathrm{SE} \pm 5 \%$ or less.

The plasma concentration of six dogs given $1.0 \mathrm{mg} \mathrm{kg}^{-1}$ of PCP i.v. is illustrated in Fig. 5 . Mean $\pm \mathrm{SE}$, plasma levels of $85.90 \mathrm{ng} \mathrm{ml}^{-1} \pm 10.8$ were found 30-45 min later when the dogs tried to lift their heads as a sign of partial recovery from anesthesia. While anesthetized, the dogs exhibited nystagmus, salivation, analgesia and pupillary dilatation. An emergence delirum of varying intensity was noted subsequently. This began approximately $45 \mathrm{~min}$ after injection and lasted up to $3 \mathrm{~h}$ with corresponding mean $\pm \mathrm{SE}$ plasma

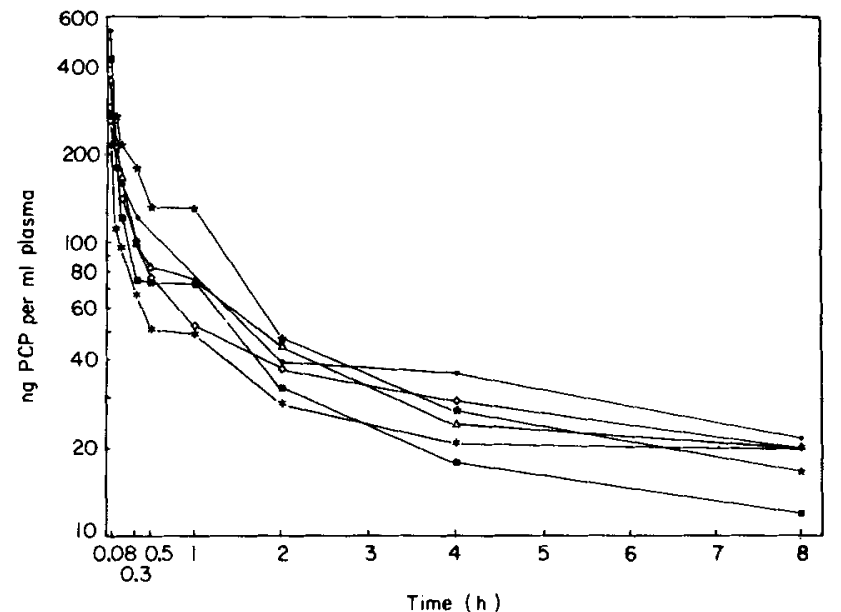

Figure 5. Dog plasma phencyclidine concentration-time course. PCP was given in a dose of $1.0 \mathrm{mg} \mathrm{kg}^{-1}$ i.v. to six dogs. Each symbol represents the plasma PCP level of a different animal over an $8 \mathrm{~h}$ period.

PCP levels of $61.6 \pm 7.2$ and $35.1 \pm 2.7 \mathrm{ng} \mathrm{ml}^{-1}$ respectively.

The plasma levels of PCP in individual monkeys given $1.1 \mathrm{mg} \mathrm{kg}^{-1}$ of PCP i.v. are shown in Fig. 6. At approximately $1 \mathrm{~h}$, monkeys became conscious with mean $\pm \mathrm{SE}$ plasma levels of $110.0 \pm 6.3 \mathrm{ng} \mathrm{ml}^{-1}$. The monkeys recovered over the next $3 \mathrm{~h}$ but did not show any emergence delirium in contrast to the dogs. The dogs were fully recovered by $8 \mathrm{~h}$ at which time levels were $18.8 \pm 2.8 \mathrm{ng} \mathrm{ml}^{-1}$. No PCP was detectable in dog plasma $24 \mathrm{~h}$ after injection.

Figure 7 and 8 represent the computer printouts for a two compartment model of the mean data for the six dogs and monkeys, respectively. Note that the predicted and observed points are very similar. The equations for each are given on the figures. The plasma PCP pharmacokinetic analysis of the individual animals and the group means are given in Table 1 for the dog ( $8 \mathrm{~h}$ data) and Table 2 for the monkey ( $4 \mathrm{~h}$ data). The SD and $95 \%$ confidence limits are indicated.

Although the monkeys received $10 \%$ more PCP, their plasma levels are much higher than expected. Part of this may be explained by the following. The mean body weight of the seven monkeys was $4.87 \mathrm{~kg}$. The

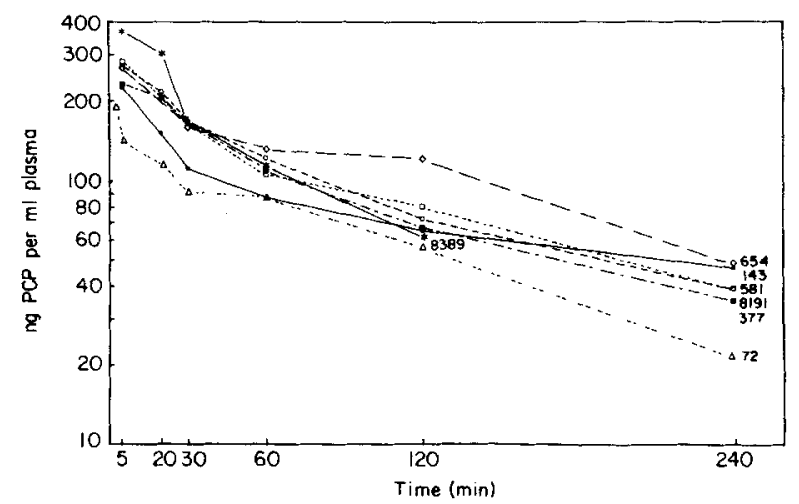

Figure 6. Monkey plasma phencyclidine concentration-time course. PCP was given in a dose of $1.1 \mathrm{mg} \mathrm{kg}^{-1} \mathrm{i} . \mathrm{v}$. to seven monkeys whose numbers are given. Each symbol represents the plasma PCP levels of a different animal over a $4 \mathrm{~h}$ period. 


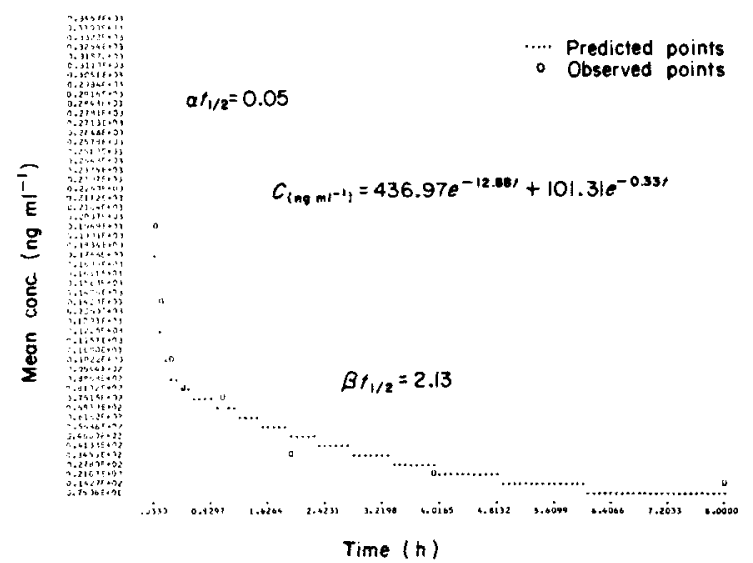

Figure 7. Computer plot of observed and predicted mean plasma levels of phencyclidine in the dog. The plasma concentration is plotted over an $8 \mathrm{~h}$ interval following a dose of $1.0 \mathrm{mg} \mathrm{kg}^{-1}$, i.v.

mean body weight of the five dogs with complete pharmacokinetic data was $18.96 \mathrm{~kg}$. The apparent volume of distribution was calculated as

$$
V_{\text {central }}=\frac{\text { Dose }}{A+B} \text { and } V_{\text {peripheral }}=V_{\mathrm{c}} \times \frac{K_{12}}{K_{21}}
$$

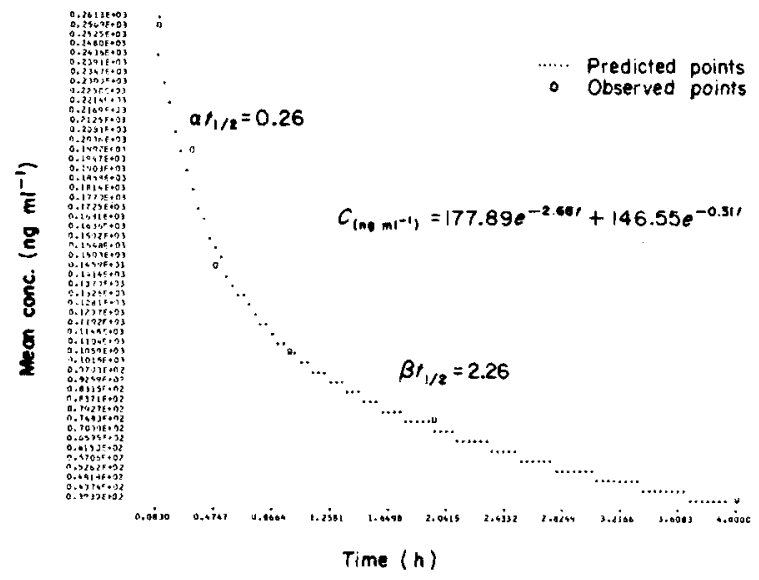

Figure 8. Computer plot of observed and predicted mean plasma levels of phencyclidine in the monkey. The plasma concentration is plotted over a $4 \mathrm{~h}$ interval following a dose of $1.1 \mathrm{mg} \mathrm{kg}^{-1}$, i.v.

If we use the computer estimated mean for each compartment then the monkey has a mean central volume of distribution $16.5 \mathrm{I}$ compared with 35.21 in the dog. The mean volume of the peripheral compartment in the monkey was 12.11 compared with 99.21 in the dog. In the monkey $K_{21}$ and $K_{12}$ are very similar,

Table 1. Pharmacokinetic parameters of phencyclidine in the dog"

\begin{tabular}{|c|c|c|c|c|c|c|c|c|c|c|c|}
\hline \multirow{2}{*}{ Dog } & \multirow{2}{*}{$A^{b}$} & \multirow{2}{*}{$B$} & \multirow{2}{*}{$\alpha^{c}$} & \multirow{2}{*}{$\beta$} & \multirow{2}{*}{ Co } & \multirow{2}{*}{$K_{21}$} & \multirow{2}{*}{$\kappa_{2}$} & \multirow{2}{*}{$K_{12}$} & \multicolumn{2}{|c|}{$t 1 / 2 \quad(h)$} & \multirow{2}{*}{$r^{d}$} \\
\hline & & & & & & & & & $\alpha$ & $\beta$ & \\
\hline 1 & 332.62 & 84.20 & 9.630 & 0.270 & 442.38 & 2.156 & 1.207 & 6.569 & 0.072 & 2.57 & 0.994 \\
\hline 2 & 226.62 & 63.15 & 4.957 & 0.136 & 292.69 & 1.037 & 0.651 & 3.405 & 0.140 & 5.10 & 0.997 \\
\hline 3 & 338.46 & 74.15 & 17.622 & 0.355 & 319.38 & 4.100 & 1.524 & 12.352 & 0.039 & 1.95 & 0.985 \\
\hline 5 & 178.77 & 123.24 & 1.895 & 0.234 & 281.79 & 0.706 & 0.628 & 0.795 & 0.366 & 2.96 & 0.976 \\
\hline 6 & 775.91 & 85.29 & 23.830 & 0.402 & 807.10 & 3.137 & 3.052 & 18.050 & 0.029 & 1.72 & 0.997 \\
\hline Mean & 370.42 & 86.01 & 11.588 & 0.279 & 428.67 & 2.227 & 1.412 & 8.234 & 0.129 & 2.86 & 0.990 \\
\hline $\pm S D$ & 236.83 & 22.65 & 9.059 & 0.104 & 221.02 & 1.420 & 0.992 & 6.977 & 0.139 & 1.35 & 0.009 \\
\hline Computer estimated mean & 436.97 & 101.31 & 12.880 & 0.326 & 458.09 & 3.104 & 1.350 & 8.748 & 0.054 & 2.13 & 0.994 \\
\hline \pm Confidence limits & - & 一 & 一 & - & 201.52 & 2.306 & 0.826 & 7.737 & - & - & - \\
\hline
\end{tabular}

Table 2. Pharmacokinetic parameters of phencyclidine in the monkey"

\begin{tabular}{|c|c|c|c|c|c|c|c|c|c|c|c|}
\hline \multirow[t]{2}{*}{ Monkey } & \multirow[t]{2}{*}{$A^{b}$} & \multirow[t]{2}{*}{ B } & \multirow[t]{2}{*}{$\alpha^{c}$} & \multirow[t]{2}{*}{$\beta$} & \multirow[t]{2}{*}{ Co } & \multirow{2}{*}{$K_{21}$} & \multirow[t]{2}{*}{$K_{2}$} & \multirow{2}{*}{$K_{12}$} & \multicolumn{2}{|c|}{$t 1 / 2 \quad$ (h) } & \multirow[t]{2}{*}{$r^{\mathrm{d}}$} \\
\hline & & & & & & & & & & & \\
\hline 1 & 96.34 & 204.80 & 2.753 & 0.330 & 296.16 & 1.962 & 0.463 & 0.658 & 0.252 & 2.10 & 0.980 \\
\hline 2 & 153.28 & 127.78 & 23.844 & 0.408 & 276.62 & 11.075 & 0.878 & 12.299 & 0.029 & 1.70 & 0.995 \\
\hline 3 & 342.58 & - & 1.108 & - & 373.50 & - & 1.108 & - & 0.625 & - & 0.957 \\
\hline 4 & 110.61 & 149.57 & 1.638 & 0.358 & 259.30 & 1.070 & 0.547 & 0.378 & 0.423 & 1.94 & 0.992 \\
\hline 5 & 116.08 & 133.88 & 1.764 & 0.274 & 302.02 & 0.856 & 0.563 & 0.618 & 0.393 & 2.53 & 0.998 \\
\hline 6 & 246.95 & 104.73 & 4.270 & 0.184 & 325.12 & 1.429 & 0.550 & 2.475 & 0.162 & 3.77 & 0.999 \\
\hline 7 & 172.55 & 157.58 & 3.257 & 0.326 & 338.06 & 1.613 & 0.657 & 1.312 & 0.213 & 2.13 & 0.999 \\
\hline Mean & 184.05 & 146.37 & 5.519 & 0.313 & 310.11 & 3.001 & 0.681 & 2.957 & 0.300 & 2.36 & 0.989 \\
\hline$\pm \mathrm{SD}$ & 85.22 & 34.01 & 8.152 & 0.077 & 38.70 & 3.970 & 0.231 & 4.640 & 0.201 & 0.74 & 0.015 \\
\hline Computer estimated mean & 177.89 & 146.55 & 2.677 & 0.307 & 297.12 & 1.379 & 0.591 & 1.013 & 0.259 & 2.26 & 0.995 \\
\hline \pm Confidence limits & - & 一 & - & - & 104.70 & 0.381 & 0.382 & 1.789 & - & - & - \\
\hline $\begin{array}{l}\text { The data of monkey } \# 3 \text { a } \\
A, B \text { and } C o \text { are } \mathrm{ng} \mathrm{m}^{-1} \text {. } \\
\text { All rate constants } \mathrm{h}^{-1} \text {. } \\
{ }^{\mathrm{d}} \mathrm{r}=\text { correlation coefficient. }\end{array}$ & 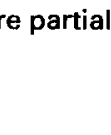 & & & no & uded. & & & & & & \\
\hline
\end{tabular}


while in the dog $K_{12}$ appears larger than $K_{21}$. The dog has a higher excretion rate constant. Both species have similar plasma half-lives in the $\beta$ phase.

It should be pointed out that volumes of distribution are mathematical artifacts that usually are referred to as 'apparent' or 'effective' volumes to indicate this fact and to emphasize they have no anatomical significance. Furthermore, a comparison of clearances of phencyclidine in the two species would be meaningful. Obviously, further analysis of the plasma pharmacokinetics of PCP are indicated with earlier and more frequent time points in both species. The reliability of the first order multicompartmental model should also be tested by varying the dose administered. The methods employed herein do indicate the remarkable utility of GCMS techniques in analyzing this problem further.

\section{Acknowledgement}

The authors wish to thank Drs D. Lin and R. Foltz of the Battelle Institute, Columbus, Ohio for the pentadeuterated phencyclidine. Phencyclidine $\mathrm{HCl}$ (batch \#277239) was obtained from Dr D. McCarthy of Parke Davis and Company, Ann Arbor, Michigan 48106. We also wish to thank Dr Wagner of the University of Michigan, Ann Arbor, Michigan 48109 whose pharmacokinetic programs Automan and Nonlin were invaluable.

\section{REFERENCES}

1. G. F. Kessler, J. Demers, C. Berlin, and R. W. Brennan, N. Engl. J. Med. (1974) 291, 979.

2. J. M. Rainey and M. K. Crowder, J. Am. Med. Assoc. 230 (Lett.) 824 (1974).

3 J. W. Eastmann and S. N. Cohen. J. Am. Med. Assoc. 231, 1270 (1975).

4. R. C. Gupta, I. Liu, G.-L. Oei and G. D. Lundberg, Clin. Toxicol. 8, 611 (1975).

5. P. C. Reynolds, Clin. Toxicol. 9, 547 (1976).

6. R. E. Ober, G. W. Gwynn, T. Chang, D. A. McCarthy and A. J. Glazko, Fed. Proc. Fed. Am. Soc. Exp. Biol. 22, 539 (1963).

7. A. J. Glazko, Antimicrob. Agents and Chemother. 3, 660 (1966).

8. J. E. Lindgren, C. G. Hammar, R. Heisling and B. Holmstedt, Am. J. Pharm. 141, 86 (1969).

9. C. G. Hammar, B. Holmstedt, J. E. Lindgren and R. Tham, Adv. Pharmacol. Chemother. 7. 53 (1969).
10. N. C. Law, V. Aandahl, H. M. Faber and W. A. Milne, Clin. Chim. Acta 32, 221 (1971).

11. L. K. Wong and D. Biemann, Clin. Toxicol. 9, 583 (1976).

12. D. C. K. Lin, A. F. Fentiman, R. L. Foltz, R. D. Forney and I. Sunshine, Biomed. Mass Spectrom. 2, 206 (1975).

13. W. D. McLeod, D. E. Green and E. Seet, Clin. Toxicol. 9, 561 (1976).

14 J. A. Marshman, M. P. Ramsey and E. M. Sellers, Toxicol. Appl. Pharmacol. 35, 129 (1976).

15. J. G. Wagner, E. Novak, L. G. Leslie and C. M. Metzler Int. J. Clin. Pharmacol. 1, 261 (1968).

Received 20 January 1977

(C) Heyden \& Son Ltd, 1978 